\title{
Measurement of Social Effect in Social Entrepreneurial Ventures
}

\author{
Muhammad Ali, Ahmad Fakhruddin, Muhammad Hassan Jahangiri, Mohamad Rashid, Abdul \\ Halim Hamdi
}

\begin{abstract}
In this reality accountability has turned into an institutional foundation and measurement defines value as per increasing requirements of stakeholders. The motivation behind this paper is to address change and its effects in progress on a social level. No matter the harbinger of change is social entrepreneurial ventures, social innovation or socially obligated activities, it deciphers into a change in business as standard of the society. In this way, the dialogue of our paper spins around quality, social issue, enterprise and it associates them to the effect on social level they produce by introducing the systems used to quantify this effect and their essential reservations. The systems for measuring the societal effect found in the literature inclines toward measurement in monetary sense and it tends to disregard the significance of the psychological influence an organization may have over its objective customers. Moreover, social effect is translated from organizational aspects and of the financial specialists, disregarding the clients that are the object of the influence. Additional discoveries expose that there is no appropriate legal enactment to manage this turf and no specific regulatory frameworks to administer the social affect. Three standards are proposed supporting social effect estimation model (supportability, included quality and adaptability).

Keywords: Social effect, social change, social business enterprise, estimation, $S V$, social issue.
\end{abstract}

\section{INTRODUCTION}

A social enterprise is the activity of an entrepreneur that perceives an issue and resolves it for social advancement and as far as benefiting so as to make societal effect and SV for both the society (versatility) and business (supportability). For a superior comprehension of quantification of the social effect that is made through business enterprise, the accompanying key ideas: social innovation, social issue and social effect are explored.

In case of the primary attribute, researchers [1]; [2]; [3] concede to the way that a clear and implanted social target is a must for social entrepreneurial elements. The intrigue in

Revised Manuscript Received on February 05, 2020.

* Correspondence Author

Muhammad Ali*, Universiti Kuala Lumpur - MITEC, Johor Bahru, Malaysia. Email: Muhammad.ali16@s.unikl.edu.my

Ahmad Fakhruddin, Universiti Kuala Lumpur - MITEC, Johor Bahru, Malaysia. Email: afakhruddin.dailami@s.unikl.edu.my

M. Hassan Jahangiri, Universiti Malaysia Tererngganu, Malaysia. Email: muhammadhassanjahangiri@gmail.com

Mohammad Rashid, Universiti Malaysia Tererngganu, Malaysia. Email: mrashid.rawan@s.unikl.edu.my

Abdul Halim Hamdi, Universiti Malaysia Tererngganu, Malaysia. Email: ahalim.hamdi@s.unikl.edu.my

(C) The Authors. Published by Blue Eyes Intelligence Engineering and Sciences Publication (BEIESP). This is an open access article under the CC BY-NC-ND license (http://creativecommons.org/licenses/by-nc-nd/4.0/) breaking down the classification the term social adapts in this setting, for it alludes to social business visionaries who produce services which are intended to fulfill fundamental needs that are not tended to by any financial or social establishment. One primary distinction that is between normal business visionaries and the societal ones is that the later ones allocates a higher importance (need) to generating $\mathrm{SV}$, while economic aspect is seen as a method for accomplishing the creation of $\mathrm{SV}$ and a "fundamental stipulation to guarantee monetary sustainability" [4]. It is argued by [3] that "social business visionaries distinguish under-utilized assets - individuals, configurations, apparatus - and determine methods for their integration to fill the void in societal needs" whereas, [5] allude to social business as being "an imaginative procedure which happens in associations driven by social mission, planned to produce imaginative new answers for society needs that are unanswered, by utilizing a restricted assets base, which prompts social change and creates value". [6] characterize the social business visionary as "an individual, in a division, employing earned wage procedures to seek after a social target". A social business visionary contrasts from a customary business visionary in two vital ways - the stressed area is utilized to maintain the social trademark:

Then again, [1] for instance, contends that pretty much as the reason of a profit based firm is to make prevalent quality for its clients, social entrepreneur essentially undertakes making unrivaled value for its customers.

In case of the second attribute, the literature appears to have an alternate approach. In particular, the fruitful quest for a social entrepreneur's main goal necessitates an inventive conveyance of products or services [7]; [2]. In any case, this attestation is fairly oppressive and selective, disregarding the extent of social businesspeople and associations that are not effectively occupied with making imaginative answers for multifaceted societal problems. OECD (2011) views social innovation as "imaginative reactions to unattended social issues and needs, non-effectively handled by the State or the business sector", and all the social businesspeople presented in the report are gathered under the umbrella of (social) innovation.

To wrap things up, a few scientists contend that with a specific end goal to be considered social enterprise, the procedure needs to take after or be presented in the rationale of the business sector [8].

Published By:

Blue Eyes Intelligence Engineering

\& Sciences Publication

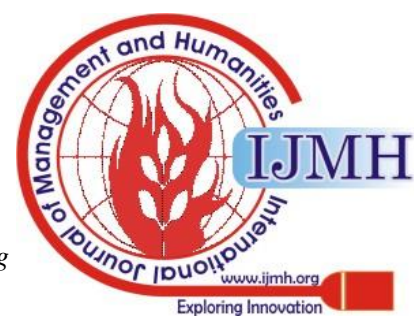


Though a few researchers and policymakers associate urgent significance to the necessity of earned pay for a man to be a social entrepreneur [9]; [10],

whereas others characterize social enterprise all the more barely, as financially supportable endeavors that create value on social level [11], paying little heed to where the income originates from. Consequently, we can comment that this is the trademark which as of now appears to get the least agreement from the analysts. This paper thus maintains the feeling of [12] whose argument that for a dare to be characterized as a social entrepreneur, it fundamentally is required to fulfill the criteria of self-sufficiency.

Table 1: Differentiations in Entrepreneurial and Social entrepreneurial approaches

\begin{tabular}{|c|c|c|}
\hline $\begin{array}{c}\text { Entrepreneurial } \\
\text { attributes }\end{array}$ & Entrepreneur & $\begin{array}{c}\text { Social } \\
\text { Entrepreneur }\end{array}$ \\
\hline $\begin{array}{c}\text { Link with social } \\
\text { issue }\end{array}$ & $\begin{array}{c}\text { indirectly effects } \\
\text { social problem - } \\
\text { socially } \\
\text { responsible } \\
\text { actions }\end{array}$ & $\begin{array}{c}\text { Income earning } \\
\text { strategies } \\
\text { linking to social } \\
\text { problem }\end{array}$ \\
\hline Performance & $\begin{array}{c}\text { Measurement in } \\
\text { Financial terms }\end{array}$ & $\begin{array}{c}\text { Dual bottom line } \\
\text { - financial and } \\
\text { social returns } \\
\text { combined }\end{array}$ \\
\hline
\end{tabular}

\section{SOCIAL ISSUES}

The reason for social issues existence is a largely considered as obvious, basically criticized for the squandering or disappointments, however the fact of the matter is that numerous of the reasons for social issues are left unmapped, and in addition to the answers, the specialists who are to be included in the fixing procedure. Along these lines, social issues are "more vague in nature; more joined with other issues; more prone to response in erratic nonlinear ways; and that is only the tip of the iceberg which is liable to deliver unpremeditated results" [13].

Since societal issues are vague and intricate, and various studies that depict them inside of the setting and the way of life they originated in, in order to comprehend and completely encounter their interconnectivity. Nonetheless, irrespective of the mixed bag of complex issues that presuppose being handled with, plentiful of these societal issues are unattended. The reason one of the fundamental missions of this century is to discover unique answers through the vision of social novelty. This is for the most part on the grounds that social innovation is centered on social issues and creation of social quality. Additionally, it " can be an item, generation procedure, or innovation... however it can likewise be a standard, a thought, a bit of enactment, a social innovation, an intercession, or some mix" [14]Social issues unite the whole group, beginning with individuals and disseminating to the whole thoughtful society, associations and governments. General public's issues were thought out to be the obligation of the municipal society, more particularly, of NGOs to explain and respond.

"In a universe of single dimensional individuals, the characteristic of the free business sector don't address social issues by any stretch of the imagination. Rather, the built-in propensity of free market to make social and natural issues. [... ] When the financial framework makes obstructions that lessen the open doors accessible to poor people, as today's framework does, then salary variations really increase instead of decreasing." [15]

Non-profit associations have made and built up a picture of creativity and authority in social issues mitigation. Be that as it may, despite the fact that new guidelines have been set and policy makers are induced to consider a few different activities for taking care of issues, they are not the singular cure or be taken as one. The necessity to address social issues lies with every single social on-screen character, beginning from the administration, open organizations, educational institutions and privately owned businesses.

Most developed countries have been attempting to devise an arrangement for tending to the most critical social essentials of the 21st century, generally at national levels. Since we can without much of a stretch recognize that numerous countries are gone up against with issues of the medicinal services frameworks and diseases, absence of essential resources, brutality and defilement, inadequate access to education, racism, discrimination and natural changes, such an arrangement has all the reason of being the main sensible development to be taken after.

\section{SOCIAL QUALITY}

The comprehension of the ideas of social enterprise and social issues might be troublesome so is the comprehension of idea of quality. The business enterprise literature has to a great extent received the researcher's position that value is communicated with trade and market exchange [16]. It was put forward by [17] that the organizations (when all is said in done) convey services and produce to the clients and the clients compensate for what they receive. This client readiness is utilized to quantify the worth that the client sees on that specific produce/benefit, with no requirement for measuring whatever else - therefore organizations get a measure of effect through the business sector implying that their exchanges make their information and their incomes (direct connection in the middle of information and income), while it is different for philanthropies; besides, he characterizes social undertakings similar to the substances which intertwine business and philanthropy, conveying social effect in a manner that is connected to creating income. [18] alluded to the subjective conclusion of worth by a buyer to recognize difference between manufacture and sale costs. Likewise, [19] takes note of the partiality encompassing value also, the part of predilections and exchanges in its establishment.

There are, then again, different types of values similar to social, common, cultural or inventive. Since value creation can at the same time allude to content and procedure, comprehending value infers overall quality as opposed to a particular feature [20],

Published By:

Blue Eyes Intelligence Engineering

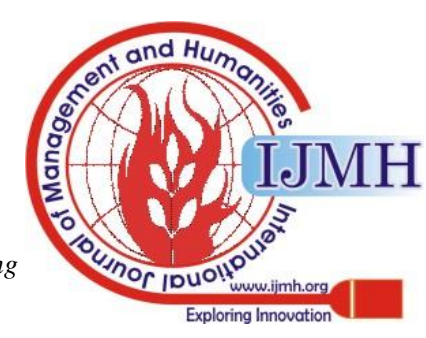


which subsequently obliges comprehension of the assessment of value and additionally the procedures included in making it.

\section{SOCIAL EFFECT}

There is no well recognized meaning of the word social effect. Social effect is the net impact of a movement on a group and the welfare of people. On the other hand, for the Social Impact Centre, Australia, societal effect implies versatile thinking led by outcomes and moves made by organizations, social purpose association, government and learning inventors that add to making an important and feasible transformation for the advantage of people and especially those at drawback as a consequence of general issues.

Social effect recognizes the positive movements in the status of individuals influenced by a particular social issue as an outcome of an activity, movement, process, venture and even strategy attempted by people, organizations, NGOs, governments etc. The effect can be certain or adverse, purposeful or unexpected, prompt and direct, or it can show later after some time and connect with distinctive individuals who were not even included in the objective, however who in an indirect way profit by the effect. We may allude to this wonder as the overspills of social effect.

\section{MEASURING SOCIAL EFFECT}

Third sector associations have been developing now like never before, and alongside public sector offices, financial specialists, funders, governments and even business organizations, they have turned out to be more distracted with rolling out positive improvements happening for society, comprehending and evaluating the measure of progress created while concentrating on the results of their exercises. As per [21], the social business people seem, by all accounts, to be using measures that identify with the venture's development (for instance the quantity of recipients) instead of the formal accomplishment of social mission. In this manner, they allude to this distinction between targets and effect estimation as the 'target estimation paradox'.

This is a characteristic error when suspecting that in ordinary organizations, development is connected with an included value, which depicts achieved objectives. The business movement has extensively used measures of effect (execution estimation) including: bookkeeping benefit, income, profit per offer, profit yield [22] and including monetary value [23]. The degree to which social business visionaries may make a generous level of monetary value, likewise these measures must be utilized, yet secondary to the measures used to assess social effect.

The literature survey produced various apparatuses effectively created for measuring social effect, the majority of which join with the effectively existent apparatuses in economy and trade. We proceed by exhibiting a rundown of their clarification and use.

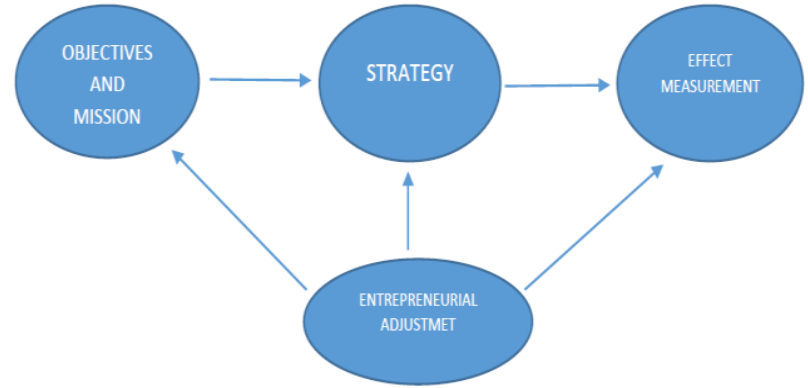

Figure 1: social entrepreneurship value created: the integration of strategy, purpose and effect extent

\section{A. Social Return on Investment}

This methodology applies routines from the social effect custom however utilizing the dialect of rate of return. The advantage of SROI assists stakeholders to perceive the greater part of the potential advantages a venture or program may have, counting more extensive financial advantage and social returns. There are numerous variations being used far and wide. The European Union's Equivalent Program unequivocally energized the utilization of measures to evaluate social and financial results. For instance, as a feature of Equivalent, Finland built up the 'SYTA strategy' for surveying social undertaking exercises. Be that as it may, REDF have withdrawn from the first prerogative that SROI could make measures on single numbers, portraying them rather as procedures for talk amid sponsors.

At the point while discussing the SROI, one must think verging on like in business, yet considering the social part. Why do social yields have to be gauged through results and effect? We represent social effect measurement in a similar manner as measuring the degree to which one entity figures out how to achieve a particular target, it aides setting up restorative measures and knows where it is at a sure point in time. In this appreciation, we emphatically energize social business visionaries to set up social destinations that are particular, quantifiable, achievable, significant /practical and time related. With regards to measuring social effect, it is vital to shoulder at the top of the priority list the accompanying key terms: Inputs, yields, results and effect.

Before going any further, give us a chance to understand the meanings of the above introduced terms: inputs $(\$ 50,000)$ - assets put resources into the movement; Yields (100 customers) - the direct substantial items from the movement, i.e., individuals prepared, trees replanted, items put up for sale; Results (20 customers picked up long-term occupation short aberrant $15 \%$ in re-offering) - changes to individuals coming about because of the movement, i.e., another occupation, expanded pay, enhanced dependability in life; Effect (17 customers) meets Results less an appraisal of what might have happened in any case (Measurement of Social Effect, 2004). This issue is significant, on the grounds that, at last, measurement defines value. It is truly intriguing how analysts figured out how to compute the SROI proportion for the Get Work element (that prepares and facilitates jobless individuals discover employments and be procured). The proportion represented 11.6:1 - implying that for each $\$ 1$ contributed, $\$ 11.6$ is made in advantage for societal benefit.

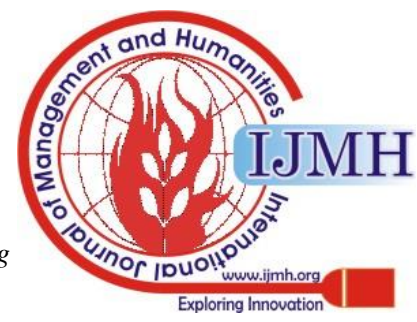


The SROI can also be utilized by individual endeavors, social organizations, financial specialists and appointing administrations. The effect for this situation is measured as far as cash, in any case, is cash the main measure of outcomes? What about the self-self-reliance the customers got, their resourcefulness and their recaptured human pride? This is likewise a social effect that adds to the betterment of general public. These components should be gauged from customers vision and indicate the social effect conveyed by the organization. This technique can be enhanced if utilized mutually with the Richter scale which is an instrument for checking diverse parts of a customer's life, for example, stress, wellbeing, certainty. This strategy can be administered sporadically.

\section{B. Triple Bottom Line}

[24] used the term triple bottom line during his tenure in a consultancy known as sustainability. The argument presented three distinctive initiatives of corporate value, people record and environment aspect. The three Ps; people, profit , planet are quantified by the triple bottom line over a time period to manifest mixed value strategies that combine social, environment and financial aspects of philanthropic ventures [25].

\section{Balanced Scorecards}

These are estimation tools for performance and for surveying whether operative exercises are adjusted to more extensive key goals. They put the social objectives of the association at the highest point of the technique, adjusting social and monetary scheming while guaranteeing budgetary manageability. In a study done in UK by [18], SEBS were found to possibly impart execution to inward and outer sponsors and present a chance to assemble trustworthiness among financial specialists, funders, clients, and stakeholders. Likewise, they were incorporated in SMEs and also in social cause associations.

\section{Life Fulfillment Measures}

Life fulfillment measures are an especially intriguing new arrangement of methodologies (drove by Teacher Paul Dolan) which think about open arrangement and social activities by assessing the additional income individuals would need to accomplish a proportional increase in life satisfaction. One inventive investigation of a recovery plan, for instance, demonstrated that ordinary interests in home wellbeing - which fetched around 3 for each penny as much as home repairs - created quadrupled value as far as life fulfillment.

\section{E. Social Reportage}

The idea revolves around the real time difference that are made by the venture within and outside the organization. The social reporting standards are scientifically applied standards that are unanimously accepted by the academics and practitioners. It is an independent document that has qualitative as well as the quantitative input on operations of an organization. This report must be mandatory for all organizations and must be furnished at regular intervals to be accessed by public. The basic format of the report has data on value addition as well the social account side which describes what kind of effect the operations has imparted on the stakeholders.

\section{F. Social Accounting}

It is a procedure for representing an association's social, ecological and financial effect and is similar to characterizing mission/vision, distinguishing stakeholders, information collection sources, making inquiries and gathering the outcomes. The social accounting system puts these outcomes into a report for an assessor to investigate. This measure may turn out to be in vain unless there is an enactment placed in spot to make social reviewing a mandatory action for each association claiming to have social effect.

\section{G. The Social Footprint Estimation}

This is a context-based way to deal with valuation based on reporting that communicates the social sustainable performance of an association by completely operationalizing the triple bottom line. It is focused on a quantifiable and contextual way to deal with viability. At the center of this estimation device there is the anthrocapital. For the effect on normal capital, the remainders utilized ought to be communicated as a part of terms of greatest and they ought to be fewer or equivalent to 1 all together for the effect to be feasible, while in case of the social base line they ought to be communicated as far as essentials (equivalent or more prominent than 1) since anthrocapital can be delivered voluntarily. Eventually the measurements rotate around cash and they are the proportion between what really is; likewise, a standard of what should be. Other than this budgetary metric, there is a non-monetary anthrocapital communicated in individual capital (wellbeing, learning, aptitudes), societal capital (individual's network) and developed capital (instruments, innovations) [19].

\section{H. Corporate Social Performance}

It is "an idea that stresses an organization's obligations to numerous stakeholders, for example, representatives and the group everywhere, notwithstanding its customary obligations to monetary shareholders" [20]. CSP has a subjective nature and it for the most part transfers on delicate measures identified with administration practices. [21] argue this incorporates work right insurance and the transparency of performance reporting on social and natural grounds.

\section{GPS for Social Effect}

The similarity of the GPS system which consolidates the signs from various satellites that triangulate a genuinely exact assessment of one's location on the surface of the terrain is utilized longitudinally, scope wise and height wise, as the impact data has three essential measurements: kind of effect the nature of impact(s) on every individual or association; size of effect - the quantity of individuals or associations influenced; and the profundity of the effect - the sum or power of progress faced, per sort of effect, per individual influenced [22]. The strategy appears to be somewhat wide and uncertain in measurement of social effect, none the less is a promising one.

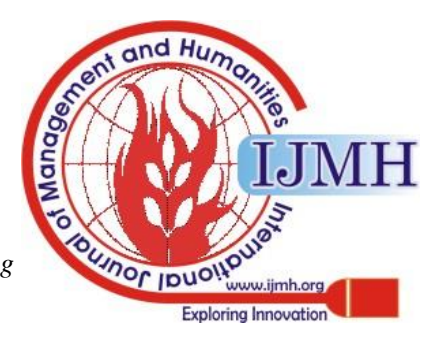




\section{STANDARDS FOR SOCIAL EFFECT ESTIMATION}

\section{A. Standards for Social Effect Estimation}

The present paper promotes that social effect can be customized and evaluated by nature of every social activity and related with the destinations focused inside of this procedure, by additionally thinking seriously about the delicate results (aptitudes, abilities, mental enhancements) that outcome from the exercises of the particular substances. It is basic for the destinations to be unmistakably verbalized and for the activities that the organization attempts to be paralleled with the effect. This procedure ought to be founded on rationale models: assets/inputs-action-outputs-results-impacts. While developing the rationale model, one ought to begin considering the effect, perusing the model in reverse. We propel the accompanying added substance standards on which social effect estimation ought to depend: standardizing stakeholder utilitarianism rule, Pareto rule and basic social effect guideline which joins the two beforehand specified standards.

\section{B. The Standardizing Stakeholder Utilitarianism Rule}

It speaks to the of mixing utilitarian reservations with standardizing stakeholder hypothesis - accept that social effect can be measured considering more noteworthy benefit (arrangement of the social issue) for the more noteworthy number of participants (who can claim consideration and whose issue is illuminated with the social activity executed) in light of the fact that their advantage have inherent value. As indicated by [23] stakeholders' benefits alongside good commitments to them ought to be at the center of corporate procedure.

Despite the fact that we are mindful of the impediments of this technique, it can speak to a equally a subjective and a quantifiable system with high appropriateness for innovative tasks that focus on social issues which influence various persons. Along these lines, plans having a superior societal effect utilizing this strategy are ventures that transform the ongoing circumstance of the social issues for the same number of persons as could reasonably be expected, and the effect measured on a short-term period.

\section{Pareto Rule}

It can be utilized as a part of terms of measuring the proficiency of the social positioned association, additionally as a method for recognizing which are the $20 \%$ of exercises/causes that are responsible for the $80 \%$ of the results/impacts. A constraint on part of this strategy is the unmistakable meaning of targets and the approach that can be used to connect them with the outcomes.

\section{Common Social Effect Rule}

Here we assert that social effect is relative with the quantity of resources following up on it and that entrepreneurial associations are not segregated but rather they are a piece of a multifaceted framework in which different specialists (comparable substances, the state, NGOs, the educated community - or different stakeholders) may attempt to look for a comparable social effect. By method for this standard we support for measuring as a total capacity the normal social effect that is conveyed by social elements on the objectives bearing as a top priority that very nearly $20 \%$ of the accumulated exercises are in charge of $80 \%$ of the outcomes. This can likewise be alluded to or figured as specific social effect being a specific situation where the quantity of sources applying effect is equivalent to 1. [26] produced this guideline from Social Effect Hypothesis. It comprises of three principles: the first expresses that social effect effects through the activity of societal powers: quality of the resource of effect, promptness of the occasion and the quantity of resources applying the effect; the subsequent principle positions that the measure of effect is connected with the sum of resources and the third manage alludes to the quantity of the objective which additionally impacts the social effect significance - as an aftereffect of scaling up, the more focuses there are, the less effect every objective gets - we clarify this procedure as taking after: to start with the association focuses every one of its endeavors on a particular total of persons - concentrated social effect, and as it broadens the objective number the endeavors dispensed to every individual element broadening social effect. In this way the social effect is characterized as an element of quality (impact, power, [psychological effects] or force of the source identified by the objective), instantaneousness (how current is the appraisal associated with the timeline when the movement happened) and number of individuals (the quantity of sources following up on the objective).

\section{E. Proposed Model for Social Effect Estimation}

By joining the data drawn from the three standards and literature review, we came to the assumption that the estimation of social effect ought to depend both on several techniques from both sides of the spectrum. We have conceived a social effect estimation model in Figure 2 which includes three classifications of components that ought to assist in measurement of collective effect: supportability, included quality and adaptability. As far as supportability (should be ascertained or if nothing else anticipated for a intermediate to long haul period, 7-10 years), one ought to distinguish the sources used to support the element and its exercises, for example, own income, aids - conditionally constant, assessment of who makes the aids, the amount of do they give and their inclination to keep giving - investments, competitions) while sufficiently having HR. Included quality alludes the mental impacts, social impacts, financial impacts, ecological and political variables (if the principle action of the organization identifies with political matters). Adaptability (or overflows) gauges the capability of extension, the indirect impacts, media scope (social consciousness) or even administrative changes.

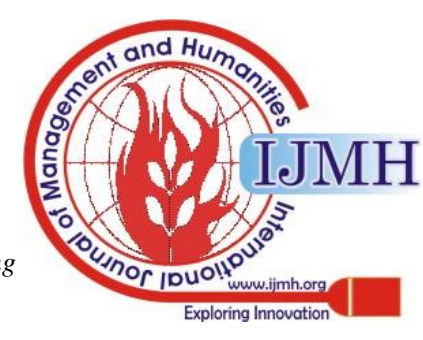




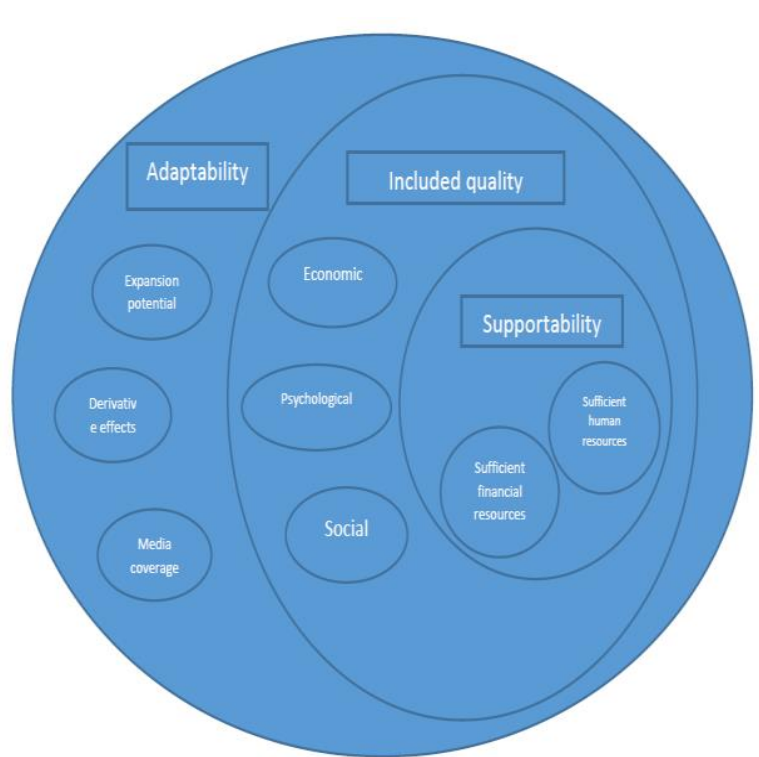

Figure 2: Proposed Model

Introducing all the three classes in a solid case: Roshni Organization established in 2015. The organization delivers capacity building and skill development in underprivileged women population. It presently keeps running within the standards of a societal venture and it is an approved protected unit, with 13 workers out of which 9 originate from childcare homes or have dissimilar forms of handicaps - it handles the issue of societal and skillful rehabilitation. The workday lasts seven hours, each week for four days.

As far as supportability, the organization receives funding from various stakeholder organizations for variety of projects and by sale of clothing and handicraft products (30\% of the aggregate income on record). They have not enlisted yet any profits. The human resource appears to be satisfied, pleased and keen to be working later on in the social venture. There have not been any resignations in this way, and when the organization aimed to multiply operations and include more individuals to the group, they got various 16 hopefuls on the awaiting list. At present the workers' well-being has not been adversely changed contrasted with the first day they came to work. It can safely be concluded that this protected unit is sustainable.

With respect to value addition, the accompanying inquiries ought to be asked both from the workers' viewpoint and of the business: are these people better coordinated in their gatherings of companions/ associates?, have their anxiety levels lowered or enhanced?, would they say they are more satisfied?, have they turned out to be more tolerant?, did their certainty/self-assurance expanded?, has their nobility been reestablished?, are they independent now ?, would they be able to figure out how to function in an alternate organization?. The response to these inquiries ought to be a pointer of the social effect an organization has. The representatives have ventured to every part of the separation from being communally sustained individuals (recipients of societal aides) to turning into the fundamental characters effectively involved in supporting the improvement of their neighborhood group and adding to moving the attitudes identified with the work performed by vulnerable individuals.

According to versatility we measure the business' capability to grow: they plot to broaden their group by adding new segments of items which hopefully will attract new representatives; the media (particularly online) is always expounding on Roshni Organization since the time that it was launched. Additionally, here we estimate the informal organizations of the workers and the quantity of personnel they collaborate with so as to get an indicated approximation of prospective subsidiary recipients; what number of them would suggest their organization. In the same way we ought to gauge the organization's systems since: distinctive sorts of coordinated efforts between social associations and organizations may expand social effect as per the knowledge gave by [27] and organizations tending to the same target may go about as another source beside Roshni by adding to an increment in social effect as per the regular social effect guideline.

The model we present is practical for it contemplates the mild angles (mental impacts) of the social effect that associations have on their objective clients/recipients, it is layered implying that it begins from some essential added substance standards and presumptions in view of the writing. It can be effortlessly adapted by specificities of every organization and it implants, to the best of our insight, interestingly the thought of regular social effect estimation.

\section{RESULTS}

The detailed analysis of the techniques that are in effect to measurement the social effect of social entrepreneurial ventures encompasses the reality that no one method is suitable and can be applied across the board for measurement purposes. The objectives of such entrepreneurial endeavors vary and also the timeline required for the effects to materialize. All the methods mentioned above satisfy the need for the measurement of social effect one way or the other but still a gap remains for a unilateral approach to justify the measurement of social effect. Scholars have contended that the workings of a social enterprise differ from a business enterprise on various levels and hence the measurement of an outcome is not the sole objective of the operations of the social enterprise. Still approaches have been developed based on the models of social enterprises and sectors in which they operate.

\section{CONCLUSION}

Making a general method for measuring social effect, one that is conspicuous anyplace on the planet, implies that the diverse issues that distinctive areas are confronted with, which fall inside of the same classification, for example, for instance hunger or poverty, can be assessed with the same devices. That can be an obstruction as we would anticipate the regions that have a poverty predominance, to enlist a more noteworthy social effect when entrepreneurial activities are discussed, furthermore, a higher level of enterprise. The enigma is that they don't, and the clarification can be instituted in the Maslow's pyramid. As per GEM when individuals must give more consideration regarding survival, they would therefore end up in a connection where settlements support standard business above socially inclined ones.

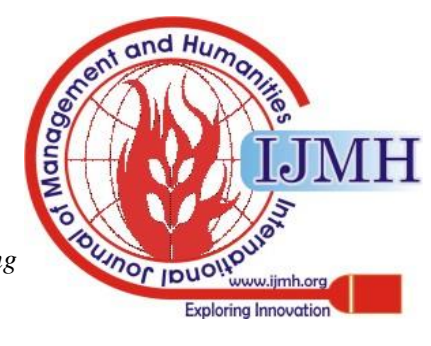


In inference, areas that are highly influenced by auxiliary disparity, of holes inside of the framework and absence of solution suppliers, are the territories in which societal outcome can't be quantified, however it would be noticeable the best.

Additional essential problem adjacent to how to quantify societal effect is timing. Since the purpose of every socially inclined association is defined as a social cause or a target, it is just characteristic that their methodology seeks after a moderate or time-consuming premise. If they somehow managed to tail them on an interim system, other state associations would have likely handled with them. Along these lines, the critical aspect here is at what time or to what extent associations start to gauge the consequences of their activities.

As per [28] it is of a most extreme significance to distinguish what changes should be measured with the goal we should have the capacity to narrate the tale of the progressions acquired in the life of the concerned customers. This estimation has four steps in which points are transformed into markers which are the descriptors documented at the beginning and toward the completion of and targets are characterized, on the grounds that regardless of the movement which is to be sought after, it will be guided by all these five components, particularly values - in light of the fact that these progressions are hard to calculate, they will be alluded to as "easy results". The procedure comprises of the accompanying:

1. What characterizes as the change?

2. Who is the source of the inquiry?

3. What inquiries to be requested that all together distinguish the change?

4. The space covered; the creators claim that the product Social Effect Tracker is by all accounts the perfect arrangement for this situation.

We trust that the need to gauge the social effect is a consequence of both inside and outer requests to have the capacity to enhance the execution of organizations, NGO's and governments and to make investment choices that amplify these effects. It is strange to look for an exceptionally and generally utilized system for measuring social effect, yet we urge for the presence of globally recognized measures that may manage this field. As indicated by the Impact Measurement Roadmap, associations will get to an execution estimation framework for social event, breaking down and conveying the outcomes and taking the obliged activities keeping in mind the end goal to move forward those effects, in the wake of having beforehand characterized the effects anticipated that would arise from the association's activities and picking the suitable measurements [29]. We likewise recognize that sure stakeholders (financial specialists, authorities, society) will need homogenous routines for evaluating the social effect with the end goal, however the social associations themselves ought to have an input in this matter. Additionally, the stakeholders ought to likewise be included on the grounds that organizations need to comprehend what results will be experienced by stakeholders as an activities' result come out.

A defeat of the introduced measures in a social business is their evaluation of the effect in monetary sense, ignoring the shift procedure. In the manner values, mission, idea points

psychological effect they impart on the destitute groups, for example, reestablishing their pride or increasing their independence.

Until now we couldn't discover any proof of enactment or a managing entity in the field of social effect measurement. There are no deliberate procedures for assembling and dissecting data about effects [30]. Be that as it may, there are a few private activities in this appreciation (Social Enterprise Mark claiming to be the main UK body to autonomously demonstrate an association puts its benefits towards societal goodness; and Community for Social Impact, Australia assumes the liability for creating sooner rather than later a hypothesis of progress for each of the components in their structure comprising quantifiable markers of change).

We impart the insight of [31] insisting that any way to deal with quantifying social effect that exclude an exchange of control to stakeholders is simply advertising; stakeholders must have genuine control to authorize responsibility and advantage from social proceeds. If we somehow happened to look at the monetary component with the instrument in social effect we discover: no enactment, no obligatory standard reportage and no necessary social review. We require a controller element in this arena to navigate, any organization that asserts to have the slightest social effect will need to back the declaration by showing social records that accord with the point of view of those influenced; consequently we require open strategy to control this.

\section{REFERENCES}

1. L. E. Orhei, S. S. Nandram, and J. Vinke, "Social entrepreneurship competence: Evidence from founders of social enterprises in Romania," Int. J. Entrep. Small Bus., 2015.

2. A. M. Peredo and M. McLean, "Social entrepreneurship: A critical geography of the concept," J. World Bus., 2006.

3. B. Janiunaite and E. Gelbudiene, "Educating Social Entrepreneurs as Agents for Inclusive Innovation,” Soc. Sci., 2015.

4. K. Visser, "Social Entrepreneurship in South Africa: Context, Relevance and Extent," Ind. High. Educ., 2011.

5. C. Busch, "Substantiating social entrepreneurship research: Exploring the potential of integrating social capital and networks approaches," Int. J. Entrep. Ventur., 2014.

6. N. F. Krueger, W. D. Schulte, and J. Stamp, "Beyond Intent: Antecedents of Resilience \& Precipitating Events for Social Entrepreneurial Intentions and ... Action,” SSRN Electron. J., 2011.

7. I. Martí and J. Mair, "Bringing change into the lives of the poor: Entrepreneurship outside traditional boundaries," in Institutional Work: Actors and Agency in Institutional Studies of Organizations, 2009.

8. R. Vandor, Peter, Hansen, Hinnerk, Millner, "Supporting Social Entrepreneurs," ePub, 2013.

9. P. Sloan, W. Legrand, and C. Simons-Kaufmann, "Social entrepreneurship and cultural tourism in developing economies," in The Routledge Handbook of Cultural Tourism, 2013.

10. N. Studdard, M. Dawson, S. L. Burton, N. Jackson, B. Leonard, and W. Quisenberry, "Nurturing social entrepreneurship and building social entrepreneurial self-efficacy: Focusing on primary and secondary schooling to develop future social entrepreneurs," in Entrepreneurship: Concepts, Methodologies, Tools, and Applications, 2017.

11. P. Vandor, H. Hansen, R. Millner, and A. Asyamova, "What Does it Take to Support a Change Maker? The Effects of Organizational Maturity, Business Model and Mission Orientation on the Support Needs of Social Entrepreneurs (Working Paper)," SSRN Electron. J., 2015.

Published By:

Blue Eyes Intelligence Engineering

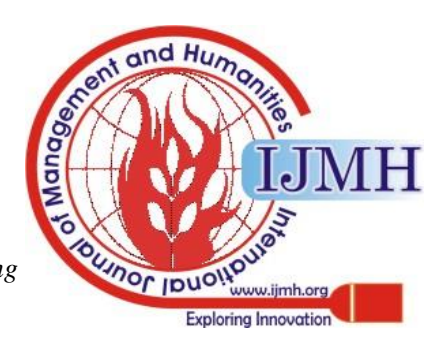


12. K. I. Mendoza Abarca, "Essays on Social Venture Antecedents, Consequences, and Strategies," ProQuest Diss. Theses, 2013.

13. S. J. Woodside, "Social mission or revenue generation?: Challenges and opportunities in social enterprise from competing institutional logics," 2016.

14. B. Dees, G \& Battle Anderson, "Scaling Social Impact| Stanford Social Innovation Review," Stanford Social Innovation Review , 2004.

15. M. Yunus, B. Moingeon, and L. Lehmann-Ortega, "Building social business models: Lessons from the grameen experience," Long Range Plann., 2010.

16. A. J. Germak and K. K. Singh, "Social entrepreneurship: Changing the way social workers do business," Adm. Soc. Work, vol. 34, no. 1, pp. 79-95, 2010

17. A. Mdee, I. Lyne, and N. Cornelius, "Social enterprise: governance, impact and measurement," Educ. Knowl. Econ., vol. 2, no. 3, pp. 149-153, 2008.

18. W. McWade, "The Role for Social Enterprises and Social Investors in the Development Struggle," J. Soc. Entrep., vol. 3, no. 1, pp. 96-112, 2012.

19. S. Caccamo, A. Voloshchenko, and N. Y. Dankyi, "The importance of creating a social business to produce low-cost hearing aids," Disabil. Rehabil. Assist. Technol., vol. 9, no. 5, pp. 368-373, 2014.

20. R. Grimm, C. Fox, S. Baines, and K. Albertson, "Social innovation, an answer to contemporary societal challenges? Locating the concept in theory and practice," Innovation, vol. 26, no. 4, pp. 436-455, 2013.

21. M. L. Shier and B. Van-Du, "Framing curriculum development in social work education about social enterprises: a scoping literature review," Soc. Work Educ., vol. 00, no. 00, pp. 1-20, 2018.

22. A. Toner, I. Lyne, and P. Ryan, "Reaching the promised land: can social enterprise reduce social exclusion and empower communities," Educ. Knowl. Econ., vol. 2, no. 1, pp. 1-13, 2008.

23. M. Loosemore, "Building a new third construction sector through social enterprise," Constr. Manag. Econ., vol. 33, no. 9, pp. 724-739, 2015.

24. T. Hindle, "Triple bottom line | The Economist," "The Economist Guide to Management Ideas and Gurus", 2002. .

25. F. Buckingham, "Idea: Triple bottom line | The Economist," The Economist, 2009

26. M. Han and B. McKelvey, "How to Grow Successful Social Entrepreneurship Firms? Key Ideas from Complexity Theory," J. Enterprising Cult., vol. 24, no. 03, pp. 243-280, 2016.

27. B. Demirel and A. K. H. Payne, "Social Innovation Adoption Behavior: The Case of Zumbara," Int. J. Innov. Technol. Manag., vol. 15, no. 02, p. 1850016, 2018.

28. S. Madon and S. Sharanappa, "Social IT outsourcing and development: Theorising the linkage," Inf. Syst. J., vol. 23, no. 5, pp. 381-399, 2013.

29. A. Salamzadeh, Z. Arasti, and G. M. Elyasi, "Creation of ICT-Based Social Start-Ups in Iran: A Multiple Case Study," J. Enterprising Cult., vol. 25, no. 01, pp. 97-122, 2017.

30. S. Mac Cormac and H. Haney, "New Corporate Forms: One Viable Solution to Advancing Environmental Sustainability," Ssrn, 2012.

31. A. Rahdari, S. Sepasi, and M. Moradi, "Achieving sustainability through Schumpeterian social entrepreneurship: The role of social enterprises," J. Clean. Prod., vol. 137, pp. 347-360, 2016.

\section{AUTHORS PROFILE}

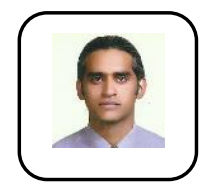

Muhammad Ali, is a $\mathrm{PhD}$ candidate at Universiti Kuala Lumpur Business School. He has an MBA and Master of Science in Management from Pakistan. He has served in Banking and NGO sector before shifting to academia.

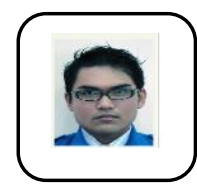

Ahmad Fakhruddin Ahmad Dailami, He has completed his bachelor in Logistic Management from University Kuala Lumpur, Malaysia. Currently, a master of Management (by Research) and Assistant Lecturer in Universiti Kuala Lumpur.

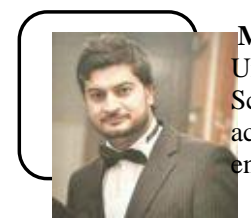

Muhammad Hassan Jahangiri, is a PhD candidate at Universiti Malaysia Terengganu. He has an Master of Science in Management from Pakistan. He has served in academia as a lecturer since 2012 and taught entrepreneurship and project management.

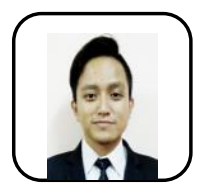

Mohamad, Rashid is currently study for a Master in Engineering Technology (Manufacturing) at the Universiti Kuala Lumpur. He had received a Bachelor in Engineering Technology in Quality Engineering from Universiti Kuala Lumpur in 2018.

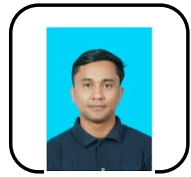

Mohamad, Rashid Abdul Halim Hamdi is a Master Engineering Technology in Electrical student at UNIKL. He is graduated from UNIKL with his course is Bachelor Engineering Technology in Electrical in 2016.

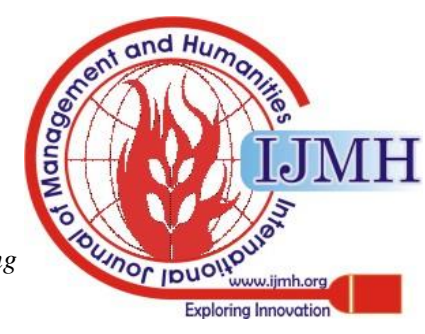

